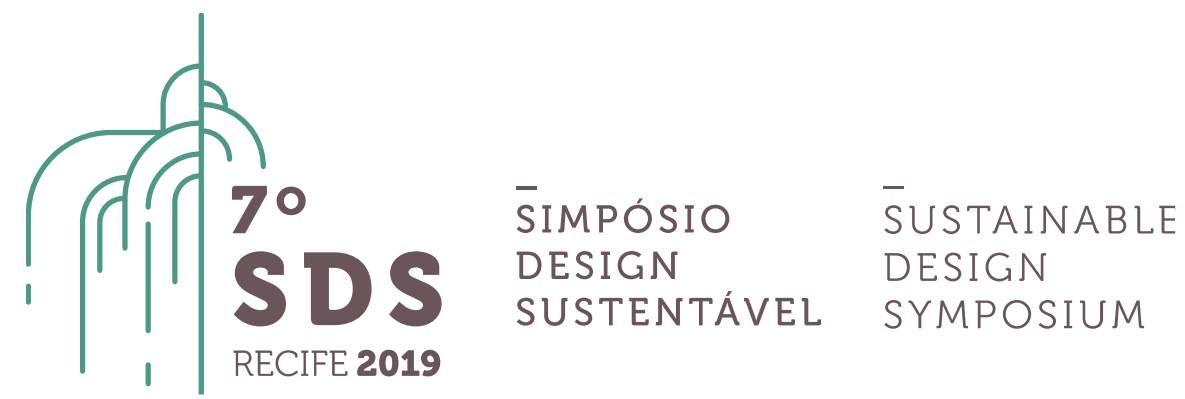

\title{
Autonomous design and sustainability through resistance, indigenous ecology and environmental feminism.
}

\author{
Zita Carolina González Guzmán¹, Raquel Gomes Noronha² \\ ${ }^{1}$ Universidade Federal de Maranhão, Mestrado em Design, zitacgg@gmail.com \\ ${ }^{2}$ Universidade Federal de Maranhão, Doutorado, raquelnoronha79@gmail.com
}

\begin{abstract}
Resume. This article seeks to understand how the autonomous design of an indigenous community is connected with environmental feminism, indigenous ecology and resistance for sustainability. Taking texts from Martínez (2017) to understand the indigenous ecology and resistances to achieve respect for mother earth. Vandana Shiva \& Maria Mies (1997), Pascual \& Herrero (2010) and Montilla \& Ledezma (2016) to talk about environmental feminism focused on indigenous communities; and finally we will review texts by Escobar (2016) and Manzini (2015) to talk about autonomous design projected by diffuse designers for sustainability. Analyzing Catalina's case and the design of a water catchment system.
\end{abstract}

Key words. Autonomous design, diffuse design, resistance, indigenous ecologism, environmental feminism, sustainability.

\section{Introduction}

There are currently different perspectives to address sustainability and ecology; this depends on the values that are linked to those that determine the problem and the solutions. If we look at it from the northern global perspective that Joan Martínez (2017) mentions in the "Ecologism of the poor", its values will be linked to capitalism and monetary value. On the other hand if we compare it with another specific group away from those values (or in combination with others that are linked to nature) we will obtain other problems and other solutions where different agents (stakeholders) play an important role within them.

The following article shows how design made by non-designers in communities of indigenous people can contribute to sustainability, triggering environmental feminism and 
resistance for an indigenous ecology. In this way, we will see the ways in which indigenous Ecologism develops. The first one, in a general way, is the resistance for sustainability; where groups of communities are organized to demand, to other types of organisms (that have a level of power over the community), the respect for the ecology values that communities have.

In the second one, a more specific case will be addressed, focused on agents of the community that are inside the home: women. Where her gender role gives her the possibility of creating an environmental feminism and allows her to exercise her autonomy for herself and her community when creating. We are going to finish with an example of a project reinterpreted and designed by Catalina (artisan of a Tzeltal indigenous community). This project is a collecting water system on the roof through gutters.

The theories that we are going to approach in the article will be about sustainability focused on communities, we are going to place indigenous ecology where the focus of conflicts is on the "use of territorial rights and ethnic resistance against the external use of resources." (MARTÍNEZ, 2017, p.341). And it's in this concept where we take the resistance as a path to sustainability where the author mentions us ways and characteristics of the various forms to take social protests.

On the other hand we will address the environmental feminism mentioned by Joan Martínez (2017), Vandana Shiva \& Maria Mies (1997), Pascual \& Herrero (2010) and Montilla \& Ledezma (2016) to talk about environmental feminism focused on indigenous communities where the role of Gender is an important part of the environment and at the same time another type of resistance for sustainability generated from the home. We are going to connect the creation of the aforementioned project with ways of doing autonomous design with texts by Arturo Escobar (2016) through the diffuse design mentioned by Manzini (2015) made by them (women of the community) for themselves and their families.

\section{Indigenous ecologism and forms of ethnic resistance.}

To start this article, it will be necessary to define the indigenous ecology and the characteristics it has, but above all we must start by addressing it from a larger perspective, where this concept is part of.

As we said at the beginning, the problems and solutions of sustainability are connected with the values of those that determine those problems and solutions. The conflict happens when different social groups with different values want simultaneously to act on the environment to support their interests. Moreover, not only that, but when the resources and environmental services of other groups want to be claimed by organizations with different levels of power to the social group with resources. In this way the conflict happens when arguing that the actions taken were made taking into account a single value system or through plural values.

The appeal to different values comes from different cultural interests and perceptions. This put, on the monetary scale, the poor are cheap and sell cheap. For the poor, therefore, it is not advisable to bet on monetary valuation, at least not as a sole criterion. (like, alias, Lawrence Summers said in 1992) (MARTINEZ, 2017, p.353)

This means that according to the interests and perceptions of those involved will be committed to the kind of values they want to take as a criterion for solutions and reach agreements. But, what would be the values that the indigenous ecologism gives importance? These depend, 
certainly, on the specific group in which this issue is being addressed. More we can refer to values that go beyond the monetary value. The author mentions two variants: one of them called sacred values, where commitments are moral with nature. This commitment characterizes, at the same time, one of the variants of environmentalism that Martínez describes as a cult to the wild. While the other variant is called as material interests, ie the "material interests for environmental resources and services that are provided by the natural environment for human subsistence." (Ibid, p.335). This last one, characterizes the environmentalism of the poor.

Both variants can resort to ancient cultural values, making use of the discourse of the sacred, rejecting the inclination toward economic value. Going to the discourse of the sacred, in addition to providing an attitude towards environmentalism and sustainability, also contributes to the popularity of those who enjoy the struggle of the ethnic groups. It is at the same time, a strong advertising manager of the movements of the indigenous communities. "The land is sacred, is something that can not be doubted in native America" (Ibid, p.335).

On the other hand, the indigenous ecology that belongs, according to Martínez, to the ecology of the poor, also called as popular ecology, the ecology of survival and sustenance, as well as the ecology of liberation and the movement for environmental justice (this last name we will return to it later to make sense of the resistance for sustainability). They name the same event or social manifestation and have their origin from the protests against the state appropriation (to mention an example) or private about the community environmental resources and especially against the disproportionate burden of contamination.

So we know that indigenous ecologism (indegenous ecology) is merely connected with social movements for environmental justice, these movements can contribute (in the words of the author) "in much to lead society towards ecological sustainability" (Ibid, p.354) and that "strong distributive conflicts can promote sustainability" (Ibid, p.354). If we go back a bit towards what the author defines as indigenous ecologism, we will find that the "focus of this conflict is the use of territorial rights and ethnic resistance against the external use of resources" (Ibid, p.341). It means that, to talk about the indigenous ecologism, is directly connected to the resistance turned towards the defense of its values on environmentalism for the sustainability.

This resistance becomes the maximum point of struggle against the opposition, but before reaching that point, the same community enters into another process called local resilience; resilience is "the ability of a system to maintain itself in spite of a disorder, without moving to a new state. It is also defined as the ability of the system to return to its original state. "(Ibid, p.77); where according to the author, is threatened by other rates of exploitation caused by the rate of capital benefit. However, there are initiatives that help maintain the resilience limits of nature, but these initiatives must arise in the direction of 'down to top' involving different agents (such as those involved in public management, as well as civil actions and mixed coalitions) with the purpose of ...

seeing a reduction of the anthropocentric impacts on the economy, society, environment, culture and diversity, to simultaneously guarantee current levels of well-being that are more ethical, equitable and coherent with reality (SAMPAIO et al, 2018 , p. 176).

But when the limits of resilience are exceeded, society moves on to another process called resistance. As mentioned earlier, this resistance is taken as a path to sustainability, where motives can be varied: such as the search for respect of human rights, external costs, value of the sacred and territorial rights, tending to confront the state by opposing the laws and/or policies 
considered destructive and unjust (according to the values of the society in resistance), doubting the mediation of the state in conflicts (since the value system will serve the interests of the state and those involved with monetary values as the main system) with the interests of external to society. Thus, it could be perceived as a betrayal of the State to the civil society, where "the poor are betrayed to give a match to the rich, whether nationals or foreigners" (MARTíNEZ, 2017, $p$ 277).

Given this panorama, we see the position of the State inclined toward the 'ecological invaders' (Ibid, p.342), that is, those societies that live off the resources of other territories and populations; betraying the 'people of the ecosystems' (Ibid, p.342), those who live off their own resources. These two groups, being in different positions, on how to obtain and manage their natural resources, face struggles that provoke this resistance. In addition to this, there is another important factor that influences these conflicts: the geographical and social distance of the centers where power is exercised that hinders the access and organization of the groups. When these requests are no longer answered, the protesters opt for other ways of confronting the conflict, appealing to a wider, even international, audience.

Some of these forms of social protests have different levels of extremism, assuming the most diverse forms.

In India, seven different forms are identified: Dharma, or sensible paralysis; Pradarshan, or mass march; Hartal, or general strike forcing stores to open their doors; Rasta Roko, or transportation blockade; Bhook Hartal, or hunger strike, placed in action in a strategic location; Gherao, which involves surrounding an official or an office for days; and, finally, the Jail Bharo Andolan, a movement whose objective is to fill the prisons in order to embarrass the State. (MARTíNEZ, 2017, p. 279)

\section{Environmental feminism, a connection between women and nature.}

Each of these forms of protest represents, at the same time, the degree of dissatisfaction of society, making demands on the state increasingly strong. However, there are other types of protests that are peaceful and individual, even become opaque or silenced by day to day; This would be the role that women play and the ways of doing for sustainability in their family and community. Take into account that "invisibility is a characteristic that the ecology of the poor shares with feminism." (MARTíNEZ, 2017, p 276).

But, why would feminism be involved in solving problems about sustainability? Before answering this question it would be good to go to the definition that the author Martínez places on environmental feminism: "Social ecofeminism and/or environmental feminism. It deals with the environmental activism of women, motivated by their social situation "(Martínez, 2017, p.341), However, the discourse of such struggles is not necessarily that of feminism or environmentalism, that is, it can be linked to interests about their family, nature and the good living (buen vivir) that the community has, of which it is part. In this way, it helps to create a common quality of life for your community. In itself, these terms, where feminism and sustainability are linked, have different perspectives on the relationships that exist within nature.

There are authors, such as Vandana Shiva and Maria Mies (1997), who see ecofeminism as a philosophy and practice born of the connection between women and nature, which places her as a feminist and about how was like and continues being constituted our system through women and their subordination, of colonization, their lands and of nature. On the other hand, it could be 
said that there are two currents of ecofeminisms: spiritualist ecofeminisms, which identify women and nature, understanding that there is an essential and natural link between them; while the other current, talks about constructivist ecofeminism, that is those who believe that the close relationship between women and nature is supported by a social construction.

In any case, both currents share that the subjection of women to men and the exploitation of the resources provided by nature are connected and respond to the logic of androcentric domination and the subordination of life (nature) to the preference of obtaining benefits (linked to the monetary value). During our history within patriarchal capitalism, it has subdued both, relegating them to invisibility.

That is why the different ecofeminist currents seek a profound transformation in the ways in which people relate to each other and to nature, substituting the formulas of oppression, imposition and appropriation and overcoming anthropocentric and androcentric visions. (PASCUAL; HERRERO, 2010, p.6)

This is how we can answer the question, which we put a few paragraphs above with what Martínez (2017) writes in his text. Women are carriers of a socially constructed role as 'providers of the oikos', what we might call home. And they are the ones who demand when there is scarcity and contamination of air, water, soil, because they threaten the survival of families. In itself, women in marginalized societies depend on common property resources, such as water, grasslands and firewood, even more than men who are more integrated into the market. The women are who react against those who try to privatize these goods, since women depend on these resources more than men, because in many cultures they have restricted access to private property.

Among rural women, according to Martínez (2017), there is a deep awareness of the human society's dependence on a clean and abundant environment, and there is a biological empathy between women and nature, whose empathy is denied to men. At least that is how essentialist ecofeminism refers to it, placing women close to nature and men close to culture, economics and politics. However, non-essentialist ecofeminists argue that the participation of women in ecological movements is the result of the commitment of the day to day that makes it strict with the use of nature and care with a healthy environment. This is why the role of women is determinant and significant in the movements of environmental justice and indigenous ecology. Assuming the leadership facing and risking being beaten, harassed, imprisoned and killed.

But at the same time, the role of women is trapped by the old community system of management of natural resources against the market and the state; it becomes dangerous for women because "traditional communities are internally unequal" (Ibid, p.282). But what would have to come up or change so that this system would not be dangerous for women? The answer is given by Martínez (2017) saying that it would be achieved with new community institutions, based on an ecological economy and ecofeminist values, without backtracking to traditions that discriminate and subordinate women.

For the creation of an ecofeminist society, we can not look at the past or the present of peasant life. We must look to the future, who knows, to an irrelevant sub-populated past of hunter-gatherers. (MARTINEZ, 2017, p.282)

The future is a good place to start this new community system, but there are still actions done by women in the old system that help direct that future, these actions are in the present and 
we find them in the indigenous communities, more specifically in Chiapas, in southern Mexico, where we can find the relationship between nature and community.

Going a bit back in history, in the 1970s, relations between nature and indigenous people were the focus of debate on environmentalism and ecofeminism (and are still under debate), where indigenous women occupy an important place.

Indigenous peoples have gained recognition as ecological actors in national and international representations, discourses and policies, where it is assumed that a female spirituality and sensitivity can be found in their traditions. (MONTILLA, LEDEZMA, 2016, p.59)

\section{Design and indigenous women; projecting autonomously for sustainability.}

What current actions does an indigenous woman have that makes changes for sustainability in her community? The answer is taken from the previous paragraphs, where the role of the woman within the community is at the same time another type of resistance generated from the home, carrying it out in a peaceful and individual way, from the bosom of her home, in the day by day, from the silence of her role as wife, mother and daughter; being her doing in the community with diverse discourses and not only that of feminism and environmentalism as mentioned by Martínez (2017), since her actions may be linked to interests about her family, nature and the 'buen vivir's (good living) in your community, even creating a common quality of life for your community. They are responsible for setting the path to the values and margins of these values for their home and among them for the community, as well as creating a shared level among the whole community of 'buen vivir'. This means that if there is a new implementation, that is helping the good living within the home of some woman, member of the community; this implementation will begin to spread to all the neighboring homes that are within the community, thus creating a level of good living within their community.

We can find this type of creation with the name of diffuse design, the design that we can all do, since it is a human practice according to Manzini (2015). We all have creativity to imagine the possible alternatives of what does not work, as a practical sense to make viable, what communities imagine. We must take into account that this design is one that is based on conventional systems, with proven and perfected forms over a long period of time. It means that, the ability to design is, first, adapted by specialized knowledge and, secondly, reinforced by daily practice, according to the author.

This makes us assume that we all have the capacity to project, since the women of the communities project artifacts and even systems without any specialized knowledge, adapted from the specialized knowledge of others and reinforced by daily practice. In addition, they have the creativity to imagine the possible alternatives of what does not work, as a practical sense so that, what they imagine, it is viable.

To make this explanation more eloquent, it will be necessary to place a project made by a woman from the community of Yochib, Oxchuc, municipality of the state of Chiapas, in southern

\footnotetext{
${ }^{3}$ The 'Buen Vivir' (Good Living) brings together the best practices, wisdom, experiences and knowledge of indigenous people and indegenous nationalities. Buen Vivir is, then, the essence of indigenous or native philosophy, in a broad sense, since it applies to everything that refers to an original population in the territory in which it lives. (ACOSTA, 2016, p.77, our translation)
} 
Mexico. This project was made in the house of Catalina Santiz, textile craftswoman and midwife of the community. This first project was decided to name it as a 'water collection system in the home' for the recognition of the work done by Catalina.

The reality that Catalina relates to obtain clean water for her home is stressful, since obtaining clean water involves a journey of 50 minutes through trails to reach the area of clean water because the nearest water area is contaminated with waste from the community.

The territory of Yochib is located in a mountainous area, with diverse flora and fauna, since it is part of the areas near the entrance of the Lacandon jungle. The flow of water is constant in this area, and rainy weather is always present in all years, reaching a rainfall of "255mm" (EL CLIMA, [2019]) as maximum in the season with the highest humidity. However, the lack of sewage system and sanitary waste management means that the use of the nearest river is for the drainage of waste from the community, including wastewater. It is important to mention that Yochib is located in a privileged area, since this community has the exclusivity of the use of the source of the river, because it is within the community area. Even the name of Yochib was adopted by the settlers, as a description of the territory. Yochibha means in Tzeltal language 'the entrance of the river'.

For a solution to obtain clean water without difficulties in the transport of the liquid and implications of the time it takes to obtain the vital resource; Catalina created a rainwater collection system through the sheet roof of her home, we have to take into account that the roof is gabled, that is, it has two faces or flat surfaces that are installed on slopes joined together in a angle. Its purpose is to make it easier for the water to slide instead of getting stuck in the roof; using the same sheet material on the sides of the roof, just where the water descends, the gutters were placed. The image presented below shows the capture system made by Catalina.

Figure 1 - The autonomous design of Catalina

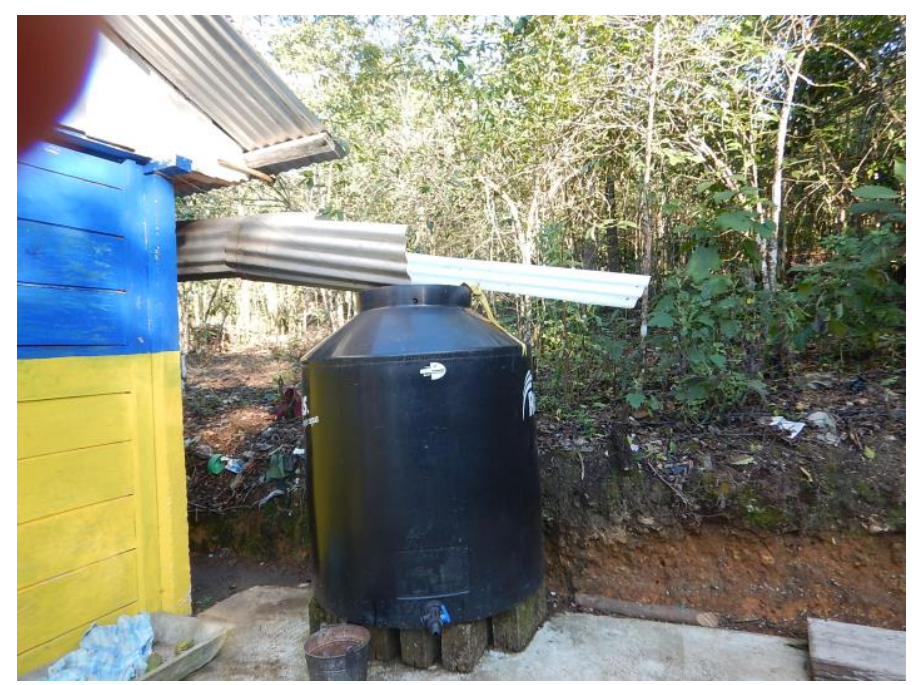

Water collection system made by Catalina. Source: Catalina Santiz (2019)

The system that Catalina implemented in her home was not invented by her, she learned it in one of the meetings of midwives from different nearby communities. However, she adapted it to the needs of her house and under the ways of making and creating it. On the other hand, this water collection system was not created in the community where Catalina had her first encounter with this system. This system was learned from the city, made by specialists in the theme of water 
collection for self-sustaining homes. Nevertheless, the adaptation of techniques, ways of doing and handling the materials found in her community was the ideation and creation of the community and at the same time of Catalina, solving the problem by means of the way of doing things that she creates.

In this specific case, the doing and knowing of Catalina produces a way of projecting autonomously, generating the system of collecting water, through the interaction with its environment, coupling with the knowledge and materials that it has within reach.

But, what does design autonomously means? To answer this is going to be necessary to define what autonomy is. According to Arturo Escobar (2016), autonomy...

[...] refers to the creation of conditions that allow the change of norms from within or the ability to change traditions traditionally. It could imply the defense of some practices, the transformation of others and the true invention of new practices. (ESCOBAR, 2016, p.197)

But at the same time, Escobar (2016) adds that autonomy describes situations in which communities relate between them and to each other, just what happens in the case of Catalina. Where the application of the water collection system was made thanks to the interaction with other communities. These other communities had interaction with the State and with private organisms, through structural coupling preserving the ways in which they regulate themselves. This is what Escobar takes from Maturana and Varela called as autopoiesis, that is, self-produced. According to the author, he mentions that autopoietic systems are open systems to the environment but at the same time closed in their operations; being open to its environment according to the degree or percentage of its operational closure, that is, the basis of the autonomy of the system.

In the case of Catalina, the difference in the way of doing by her with the specialized way of doing is concentrated in different elements with the materials: in the specialized making, the materials are made of plastic (by the continuous contact with the humidity of the environment, where the oxidation of the material should not intervene in the collection of water throughout the year). In specialized cases it is recommended to use tubular gutters (gutter of semicircular or square section that leads rainwater from a roof to a rain drain) for the transport of water to the downpipes (upper part of a rain drain that is funnel-shaped), as well as tubular conduits for the transport of water to the water storage tank. All these prefabricated materials are elaborated so that their assembly is easy. However, for a better permeability in the system, plastic films are used that mold to the connectors of the materials.

On the other hand, the processes also have differences with the doing of Catalina. In the assembly of a system made by specialists, the person in charge of this system has knowledge in the use and practice of tools and techniques for the assembly of each material. As well as the knowledge of the pieces (such as nail, screws, nuts, etc.) that are needed for the union, adjustment and fixing of the system to the house. Nonetheless, the steps to follow for the creation of the system are linear and follow a special order to save time and resources.

While in the making of Catalina, this materials were chosen by proximity (obtained in the same community), knowledge of the material (since it is the same used for the roof) and economy, since the material used is a remnant of the material used for ceiling. The components for the manufacture of the system are different, since Catalina opted to eliminate the rainwater downpipes and the connectors (funnels). On the other hand, the use of tools and parts for the 
installation and fixing of the system to the roof of the house was done with wire and without the use of nails, screws, etc.

In the same way that there were changes in the materials and tools and the use of these, we also found changes in the process such as Catalina's knowledge of the materials. Converting a roof sheet to a gutter is due to the knowledge of flexibility of the material; until the decision to section the material for the handling of angles and slopes that the gutters needed for the descent of the water towards the tank. Another important aspect about the process was the decision to place the water tank near the house, where everyone could see it. Since that allowed her to make visible the natural resource and to have knowledge of the amount of water. As well as better handling of the tank for collection, cleaning and extraction of water.

At the same time, the tank used to store the water was modified, using a plastic prefabricated water tap to extract the resource easily. By placing this key in the bottom of the tank, in this way, the water flow will be constant, even if the amount of water is scarce. Another modification of the tank was the adhesion of a base made of concrete walls, to give an elevation to the tank for better access to the water tap. At the same time, to protect it from animals, other liquids and materials that may damage it. Finally, the process followed for the placement of the system was intermittent, spiraling and with different cycles, this means that there was no linearity in these steps, since the time of execution of the processes was interfered by the time of being a mother, wife, artisan and midwife in her community. Following an order with her way of life in interaction with her family, the community and things.

Catalina's way of design brings us closer to understand that the autonomous design that she executes for herself and her community leads to exercising her autonomy to face paths where sustainability and traditional ways of doing are intertwined. We know that Catalina's design is through autonomous design, since her process, knowledge and ways of executing and planning follow autonomous design principles.

The first of the principles tells us "Every community practices the design of itself" (ESCOBAR, 2016, p. 210) involving social and environmental relationships, daily practices, organizations, ways of doing and knowing. It is a matter of involving more forms of reflection, not only objective, but abstract and bodily.

The second principle starts from the first "Each design activity must start with the premise that every person or group is a practitioner of their own knowledge and from there examine how people understand their reality." (Ibid, p. 210) At the moment when Catalina chose to execute the way of doing of herself, she chose to put into practice her knowledge and not that of the experts. Knowing in depth the limits and possibilities of a water collecting system within her reality.

"What the community designs is, in the first instance, a system of research or learning about itself" (ibid, p 210). This third principle places us co-designers (with expert knowledge) in part of the process and performers of some practices. However, learning that is in the set of experiences when designing, will not be about the expert designer, nor about the knowledge that this leads to the community, in any case, it would be about the community, the reality of people like Catalina. in the other hand "each design process implies a statement of problems and possibilities; that allows the designer and the group to generate agreements on objectives and decide between alternatives of action "(ibid, p.210). In Catalina's case, this part of the process was autonomous, taking her own decisions about the problem and the possibilities of action. As well as 
the design decisions that could affect life and housing dynamics that community and she have. Achieving different scenarios for the creation of the system.

And finally, "This exercise may involve the construction of a 'model' of the system that generates the problem of communal concern" (ibid, p.210) thus allowing to see the errors and asking what to do about it, in this way the resolution of this would be a series of criteria, practices and activities to evaluate the execution of the act of investigating and projecting.

\section{What else is left?}

What remains after this analysis is to claim our role as humans, designers, women and men for sustainability. We can review our role as designers as agents of change, influencing the decisions of other people on ways to produce and consume with a sustainable focus, they are beneficial for the environment, people and other living beings. The role of designer goes beyond projecting, is also a communicator and mediator between groups with different values and criteria of quality of life, especially if we speak of groups in resistance and struggle for sustainability.

Therefore, we must also understand and be part of the struggles that exist in terms of territory, natural resources, and human rights that seek the good living of a community. This would be one of the ways to begin the transition, to place our values in question with reference to the values of the community in fight. Understand that being part of the resistance does not mean being on strike or in battle, is to take actions from the control of our life that can change the way of life of others, as well as the role of some indigenous women in the communities. We know that the transition by choice can only take place if a large number of people recognize, in the transition itself, an opportunity to improve their level of well-being. But this degree of well-being will only be improved by implementing certain actions that lead society to see a change in their quality of life. For this it will be necessary to change the value judgments and the quality criteria that interpret the idea of well being. And to achieve this we need a change in the dominant culture.

Besides the change of values and criteria of the quality of life, the solution of the environmental problem requires other forms of economy, not only the activities outside the market, but also the activities developed informally and voluntarily. Because in a sustainable society, the idea of work must be redefined as Martinez (2017) said. Leaving aside the stereotype of work as an activity that must be developed in well-defined places and times, because this idea will enter into crisis, since this type of work disconnects the human being with naturefor this reason, this type of work will be reduced quantitatively, towards a qualitative transformation and other forms of activity will arise that do not correspond to traditional schemes, but to natural schemes of autonomy.

Let's review that the autonomy is according to Escobar (2016) to live as we like and not as they impose on us, to take life where we want and not where a pattern indicates. But this autonomy is always connected to a territory, we can not live without one. And this territory does not exist without Mother Earth and for it to exist, "it can not be enslaved, because as long as it is a slave none of us and we live to live [...] we live only to satisfy the greed of the masters of the world. And that's not the way."(Ibid, 225).

Finally, we must review our role as designers in contact with indigenous and autonomous groups and communities. According to Manzini (2006) it is necessary to design systems that allow its users to reach their objectives and develop their potential. Then, the inhabitants of the 
indigenous communities, not only need to be autonomous in the practices of resistance and projecting; They also need that designers create the space and system so that autonomy can be achieved through design. For this reason, as designers, we must promote the exercise of an autonomous design and a space to exercise it, since this makes society more receptive and sensitive to the concerns of the community. We must remember that autonomy seeks intercultural dialogue with other people in conditions of social equality. It is then that autonomy could be the key to the understanding, respect and agreement of values and criteria of quality of life (and 'Buen Vivir' for communities) that lead to sustainability in different social groups.

\section{Bibliographic references.}

ACOSTA, A. O bem viver: uma oportunidade para imaginar outros mundos. São Paulo: Autonomia Literária, Elefante, 2016.

EL CLIMA promedio em Oxchuc México. In: Weather Spark, [2019]. https://es.weatherspark.com/y/10596/Clima-promedio-en-Oxchuc-M\%C3\%A9xico-durante-todoel-a\%C3\%B1o. Acceso: 10 may. 2019.

ESCOBAR, A. Autonomía y diseño. La realización de lo comunal. Popayán: Universidad del Cauca. Sello Editorial, 2016

MANZINI, E. Design, ethics and sustainability, www.dis.polimi.it/ manzinipapers/06.08.28; Design ethics sustainability.doc, 2006.

MANZINI, E. Design, when everybody designs. An introduction to design for social innovation. London; Cambridge: The MIT Press, 2015. 241 p.

MARTINEZ, J. O ecologismo dos pobres: conflitos ambientais e linguagens de valoração. São Paulo: Contexto, 2017.

MONTILLA, M.; LEDEZMA, G. Ecofeminismo: Un Pensamiento Ambientalista de Corte Feminista. Hegemonia Revista de Relações Internacionais do Centro Universitário Unieuro, n. 20, p. 50-64, Jan-Jun 2017.

PASCUAL, M.; HERRERO, Y. Ecofeminismo: una propuesta para repensar el presente y construir el futuro. Boletín ECOS, n.o 10, p. 1-9, Jan-Mar 2010.

SAMPAIO, C. et al Design para a sustentabilidade: dimensão ambiental Curitiba, PR: Insight, 2018. $183 \mathrm{p}$.

SANTIZ C. [El diseño autónomo de Catalina]. 2019. 2272 X 1704px, 200DPI, RGB, 1/100s, ISO-125.

SHIVA, V.; MIES, M. Ecofeminismo, Icaria, Barcelona, 1997. 